\section{Endoscopic Diagnosis of Colonic Tuberculosis: Unusual Presentation with Two Colonic Strictures}

A 60 -year-old patient presented with a six-month history of nonspecific abdominal pain and marked weight loss. His hemoglobin was $10 \mathrm{~g} / \mathrm{dl}$, and the erythrocyte sedimentation rate (ESR) was $80 \mathrm{~mm} / \mathrm{h}$. The chest radiograph was normal, and gastroscopy revealed gastritis. A barium enema showed narrowing of the splenic and hepatic flexures, without obstruction (Figure 1). Colonoscopy revealed a tight stricture and multiple nodules 2 $4 \mathrm{~mm}$ in diameter at the splenic flexure (Figure 2). The tight stricture precluded examination beyond the splenic flexure. The histology of the nodules showed tuberculous granulomas composed of epithelioid and Langhans' giant cells with focal central caseation. A Ziehl-Neelsen stain showed acid-fast bacilli.

After two months of treatment with isoniazid, rifampicin, pyrazinamide. and ethambutol, and four months of isoniazid and rifampicin, he gained $10 \mathrm{~kg}$ in weight, and his hemoglobin and ESR values returned to normal. Colonoscopy showed a decrease in the number of nodules in the tight splenic flexure, and biopsies of the nodules showed only inflamed colonic mucosa, A barium enema showed persistent narrowings at the splenic and hepatic flexures. The patient remains well six months after treatment.

Colonic tuberculosis can be diagnosed in $60-80 \%$ of patients by colonoscopy $(1,2)$. Rare cases of multiple segmental colonic involvement, with mucosal nodules occurring with a single stricture, have been reported $(1,2)$. The present patient presented with two strictures affecting the splenic and hepatic flexures, a finding that has not been described previously. Colonic tuberculosis occurring together with colorectal cancer has been described (3). Although the hepatic flexure could not be accessed colonoscopically to exclude carcinoma, the fact that he improved with medical therapy made this possibility less likely. Most patients with tuberculous strictures respond to standard antituberculous drugs $(2,4)$, although a few require surgery in spite of medical treatment (2). The diagnosis of colonic tuberculosis needs to be considered when multiple colonic strictures are observed.

\section{S. S. Wong, E. Chow}

Dept. of Medicine, Our Lady of Maryknoll Hospital, Hong Kong

\section{References}

1. Shah S, Thomas V, Mathan M, et al. Colonoscopic study of 50 patients with colonic tuberculosis. Gut 1992; 33:347-51.

2. Bhargava DK. Kushwaha AKS. Dasarathy S. Endoscopic diagnosis of segmental colonic tuberculosis. Gastrointest Endose 1992; $38: 571-4$.

3. Leong AF, Seow-Choen F, Goh HS. Colorectal cancer and intestinal tuberculosis. Ann Acad Med Singapore 1993: 22 934-6.

4. Anand BS, Nanda R, Saedev GK. Response of tuberculous stricture to antituberculous treatment. Gut 1988;29:62-9.

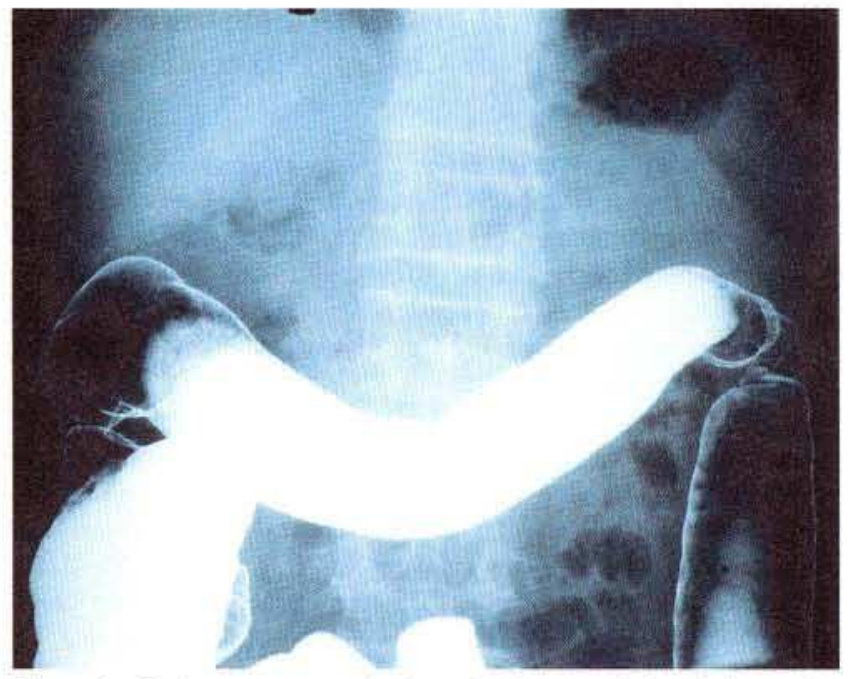

Figure 1: Barium enema examination, showing constricting lesions at the splenic and hepatic flexures

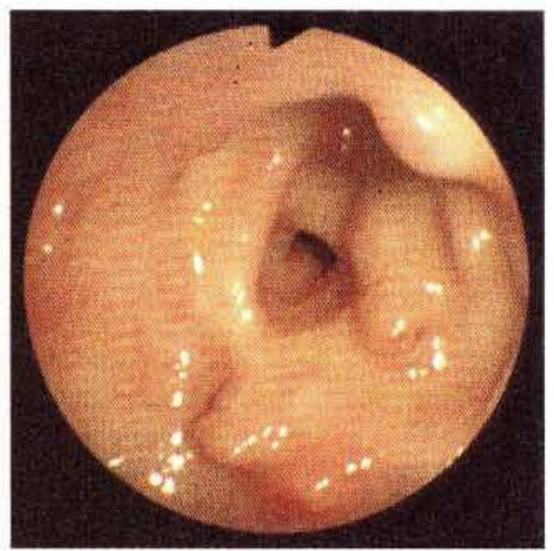

Figure 2: Colonoscopic view of tuberculosis at the splenic flexure, showing a tight stricture with nodules

Corresponding Author

S. S. Wong, M.D.

Dept. of Medicine

Our Lady of Maryknoll Hospital

Shatin Pass Road

Wong Tai Sin

Kowloon

Hong Kong

Fax: $+852-23276852$ 